\title{
Desenvolvimento e Caracterização de Membranas Rígidas, Osteocondutoras e Reabsorvíveis de Polihidroxibutirato e Hidroxiapatita para Regeneração Periodontal
}

\author{
Emily C. C. Reis, Andréa P. B. Borges \\ Departamento de Veterinária, UFV
}

Paulo M. Oliveira

Escola de Design, UEMG

Sheyla Maria Castro Máximo Bicalho JHS Laboratório Químico

\author{
Alexandre Martins Reis, Charles Luís da Silva \\ Departamento de Engenharia de Produção e Mecânica, UFV
}

\begin{abstract}
Resumo: A regeneração tecidual guiada (RTG) utiliza membranas para favorecer a regeneração dos tecidos periodontais danificados pela doença periodontal. As membranas usadas ainda apresentam limitações, principalmente quanto à capacidade de manter o espaço do defeito. Dois biomateriais de origem brasileira, a hidroxiapatita (HAP) e o polihidroxibutirato (PHB), foram utilizados para fabricar membranas rígidas para RTG, contendo 25, 35 ou 50\% de HAP em matriz de PHB pelo método de moldagem por injeção. As membranas apresentaram alta cristalinidade, sendo que, inicialmente, a topografia de superfície era pouco complexa em que os grânulos de HAP não estavam expostos. As membranas foram desgastadas com broca odontológica, de modo similar à cirurgia para sua implantação in vivo. Este procedimento resultou na exposição dos grânulos de HAP numa superfície com poros e estruturas lineares de dimensões que variaram de 3,55 $\mu \mathrm{m} \pm 1,14$ a 75,98 $\mu \mathrm{m} \pm 30,76$, portanto, característica microtopográfica. Observou-se, ainda, que a HAP é responsável por conferir uma topografia de superfície mais complexa às membranas. Portanto, espera-se que membranas com as características de rigidez e superfície microtopográfica possam proporcionar estabilidade ao defeito periodontal e permitir migração celular mais intensa, assim favorecendo a regeneração periodontal.
\end{abstract}

Palavras-chave: Regeneração tecidual guiada, hidroxiapatita, polihidroxibutirato, compósito, análise da topografia de superfície.

\section{Development and Characterization of Rigid, Resorbable and Osteoconductive Membranes Made of Polyhydroxybutyrate and Hydroxyapatite for Periodontal Regeneration}

\begin{abstract}
Guided tissue regeneration (GTR) is a technique that applies membranes to favor the regeneration of periodontal tissues lost due to periodontal disease. The membranes normally used have limitations however, mainly related to the difficulty in stabilizing the defect. In this study, two biomaterials of Brazilian origin, hydroxyapatite (HAP) and polyhydroxybutyrate (PHB), were used to make rigid membranes for GTR. Membranes were made with 25, 35 or 50\% HAP in a PHB matrix by injection molding. The membranes were highly crystalline, with an initial smooth surface topography where HAP particles were not exposed. Membranes were grinded with a dental bur, similarly to the surgery procedure for their implantation in vivo. This procedure resulted on the HAP granules being exposed on a surface with pores and linear features of dimensions varying from $3.55 \mu \mathrm{m} \pm 1.14$ to $75.98 \mu \mathrm{m} \pm 30.76$, which are thus characterized as microtopography. Additionally, HAP was responsible for a greater surface complexity. Therefore, these characteristics of rigidity and surface microtopography may be able to provide stability to a periodontal defect and allow a greater cell migration, both favoring periodontal regeneration.
\end{abstract}

Keywords: guided tissue regeneration, hydroxyapatite, polyhydroxybutyrate, composite, surface topography analysis.

\section{Introdução}

A regeneração tecidual guiada (RTG) é uma técnica bastante discutida no tratamento da doença periodontal visando a regeneração dos tecidos de suporte do dente danificados pelo processo da doença, ou seja, osso alveolar, ligamento periodontal e cemento ${ }^{[1,2]}$. Ela pressupõe a utilização de membranas entre o retalho mucogengival e o osso alveolar e raiz dentária expostos, cobrindo estes dois últimos e assim, protegendo o coágulo sanguíneo formado na região do defeito. Desta forma, com a organização do coágulo em matriz provisória, células progenitoras podem migrar do ligamento periodontal e osso alveolar, e não células do tecido gengival. Muitos estudos demonstram que essa origem das células é decisiva para a formação de novos tecidos periodontais e não de um tecido conjuntivo de reparação. Sendo assim, estas células são capazes de se depositar e se diferenciar em osteoblastos, fibroblastos e cementoblastos para o processo de regeneração periodontal ${ }^{[1-3]}$.

Membranas de politetrafluoretileno são utilizadas na RTG com bons resultados ${ }^{[2,3]}$, mas possuem como desvantagem a necessidade de uma segunda intervenção cirúrgica para sua remoção, visto que este é um material não reabsorvível ${ }^{[2,4]}$. Assim,

Autor para correspondência: Emily C. Carlo Reis, Departamento de Veterinária, Universidade Federal de Viçosa - UFV

Campus Universitário, sn, CEP 36570-000, Viçosa, MG, Brasil, e-mail: emilycarlo@yahoo.com.br 
membranas reabsorvíveis de diversos materiais, como colágeno e ácido polilático, têm sido desenvolvidas e utilizadas. Contudo, uma das principais limitações das membranas reabsorvíveis atualmente disponíveis é a capacidade de manter o espaço do defeito, ou seja, elas são excessivamente flexíveis e colapsam para dentro do defeito, ocupando-o e interferindo na formação do coágulo sanguíneo. Assim, a regeneração periodontal, principalmente do osso alveolar, é limitada, considerando que as células não têm volume de matriz provisória necessário para migrarem, se depositarem e formarem novos tecidos. Estudos demonstram que a regeneração dos tecidos periodontais é dependente da capacidade da membrana manter o espaço do defeito, sendo esse, portanto, um fator decisivo para a regeneração periodonta ${ }^{[1-3]}$.

Mais recentemente, membranas têm sido desenvolvidas com superfícies modificadas para favorecer a regeneração dos tecidos periodontais ${ }^{[5,6]}$. Em geral, a superfície interna da membrana, que ficará em contato com o coágulo sanguíneo, é trabalhada química ou fisicamente para favorecer a adesão de fibrina da matriz provisória, plaquetas e osteoblastos ${ }^{[5-9]}$. Um exemplo destas superfícies é a membrana de PGLA (ácido láctico-co-glicólico), desenvolvida por Owen et al. ${ }^{[5]}$. Estes autores utilizaram um molde contendo ranhuras e sulcos de magnitude microscópica para a dispersão do polímero líquido que, após a secagem e retirada do molde, dá origem a uma membrana com tais estruturas impressas na superfície. Ainda no tratamento de superfícies pode-se citar, dentre outros métodos, a utilização do condicionamento ácido para aumentar a complexidade topográfica de superfície de próteses ortopédicas de titânio ${ }^{[7,8]}$ e a adsorção de fibronectina para favorecer a adesão de osteoblastos ${ }^{[9]}$.

Dentro deste contexto, dois biomateriais desenvolvidos com tecnologia nacional podem ser citados, a hidroxiapatita sintética (HAP) e o polihidroxibutirato (PHB). A HAP é uma cerâmica amplamente utilizada para o preenchimento de defeitos ósseos por ser biocompatível, reabsorvível e osteocondutora, ou seja, serve como arcabouço para a migração de células osteoprogenitoras. Ela é considerada bioativa, formando uma ligação direta com o tecido ósseo, sem interposição de tecido fibroso ${ }^{[10-13]}$. Já o PHB é um polímero natural reabsorvível pertencente ao grupo dos polihidroxialcalonatos que se mostrou biocompatível ${ }^{[9,10,14,15]}$. Suas características mais importantes para utilização como biomaterial são sua lenta reabsorção, compatível com a regeneração tecidual e ótimas propriedades mecânicas ${ }^{[1,15,16]}$. Ele tem sido testado principalmente na fabricação de arcabouços para a regeneração óssea e fabricação de parafusos e placas para osteossíntese. Bons resultados foram demonstrados, tanto no que diz respeito às propriedades mecânicas quanto às características de superfície e porosidade para a migração celular, todos fatores que dependem da forma de fabricação $0^{[9-11,15]}$. Compósitos a partir da associação HAP e PHB têm sido desenvolvidos e analisados principalmente na regeneração óssea, para servir como substituto temporário para este tecido, mostrando resultados promissores ${ }^{[10,15,17]}$.

Desta forma, o presente trabalho objetivou desenvolver membranas reabsorvíveis com a associação da HAP com o PHB com duas características: i) uma membrana rígida capaz de manter sua forma, assim prevenindo seu colapso para dentro do defeito e mantendo o espaço para o coágulo; ii) uma superfície interna de topografia complexa para promover maior adesão de fibrina, plaquetas e células progenitoras, favorecendo assim, respectivamente, a manutenção do volume do coágulo sanguíneo, a sinalização que direciona a migração celular e a formação de novos tecidos. Assim, com tais características, acredita-se que estas membranas poderão ser utilizadas para favorecer a regeneração de defeitos periodontais.

\section{Material e Métodos}

As características anatômicas da face vestibular da mandíbula de cães foram estudadas, considerando que estes animais serão os futuros modelos experimentais para a aplicação das membranas in vivo. Em seguida, um modelo foi desenvolvido com base nessas características, nas seguintes dimensões: $10 \mathrm{~mm}$ de largura $\times 10 \mathrm{~mm}$ de comprimento $\times 1,5 \mathrm{~mm}$ de espessura na extremidade inferior $\times 2,5 \mathrm{~mm}$ de espessura na extremidade superior. Assim, postiços foram fabricados em aço ferramenta em cromoníquel de alta resistência com cavidades usinadas por eletroerosão de acordo com estas dimensões. A hidroxiapatita sintética (HAP-91 ${ }^{\circledR}$, JHS Laboratório Químico, Belo Horizonte) foi previamente misturada ao PHB nas proporções em
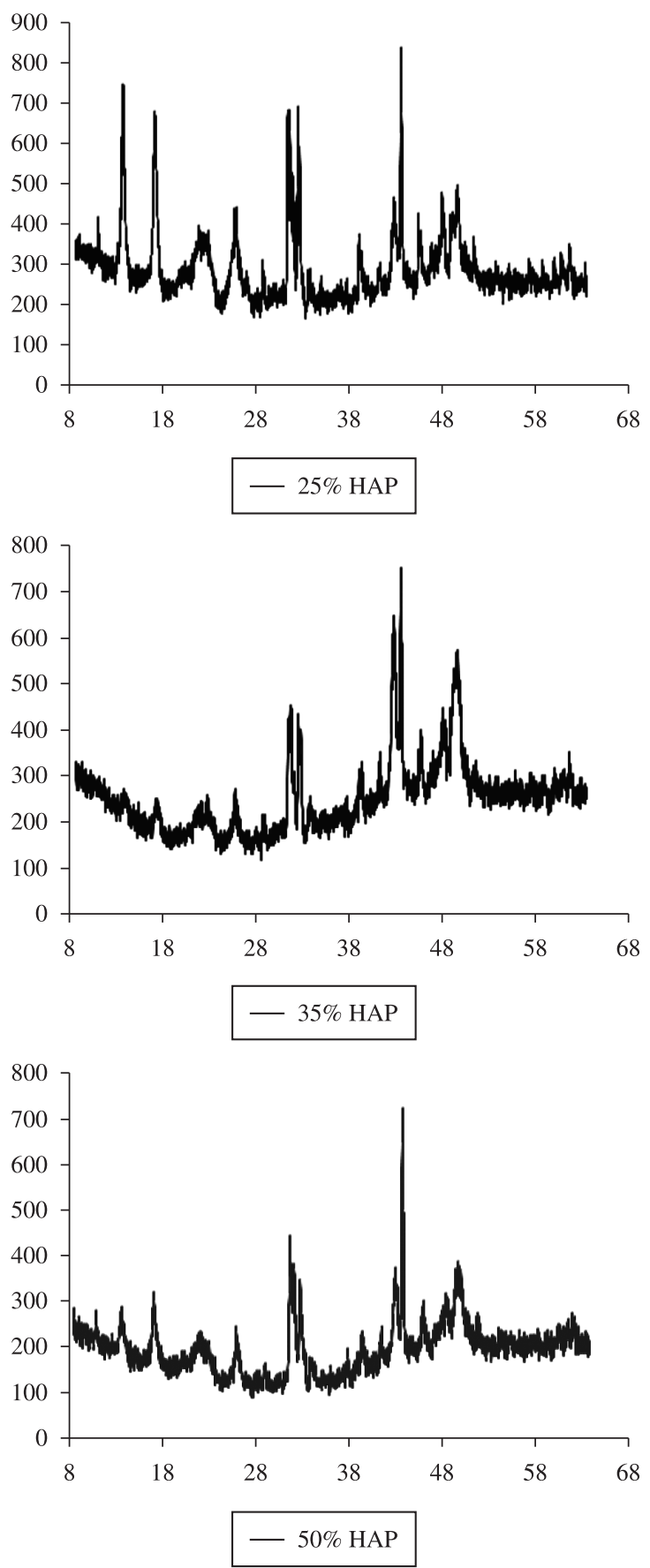

Figura 1. Difração de raios X dos compósitos de HAP + PHB. 


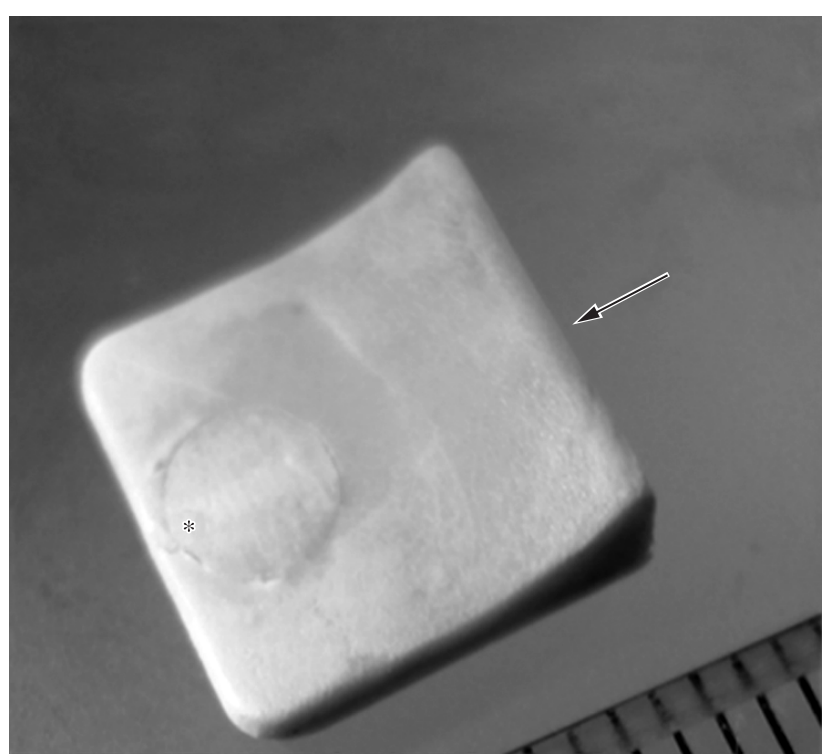

(a)

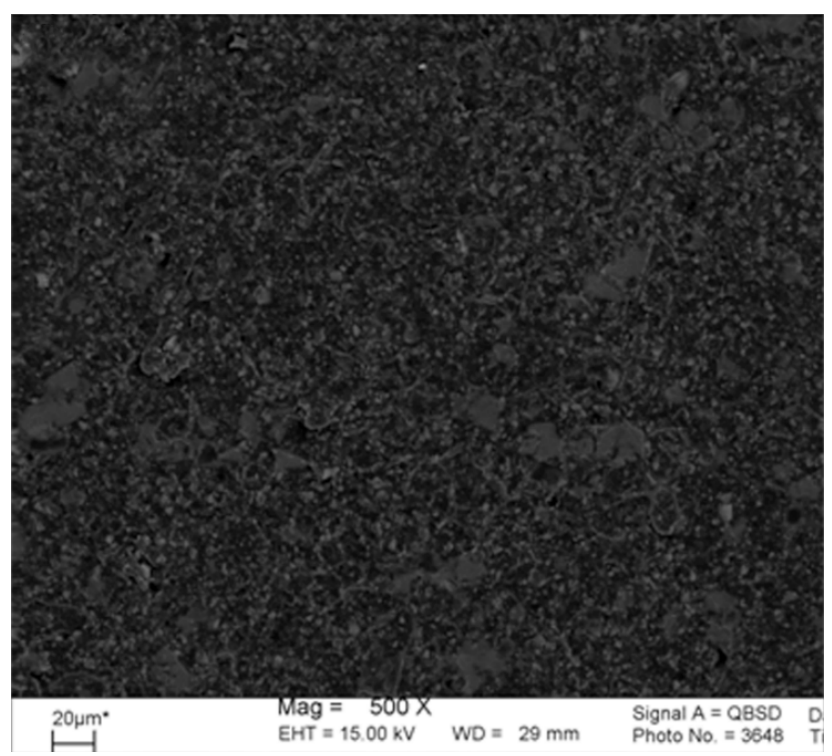

(c)

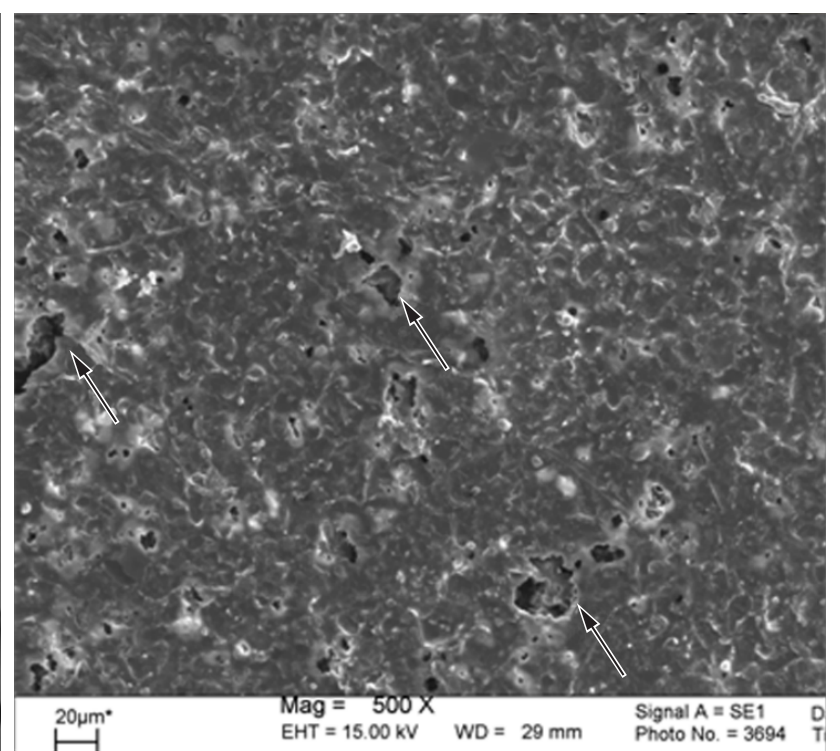

(b)

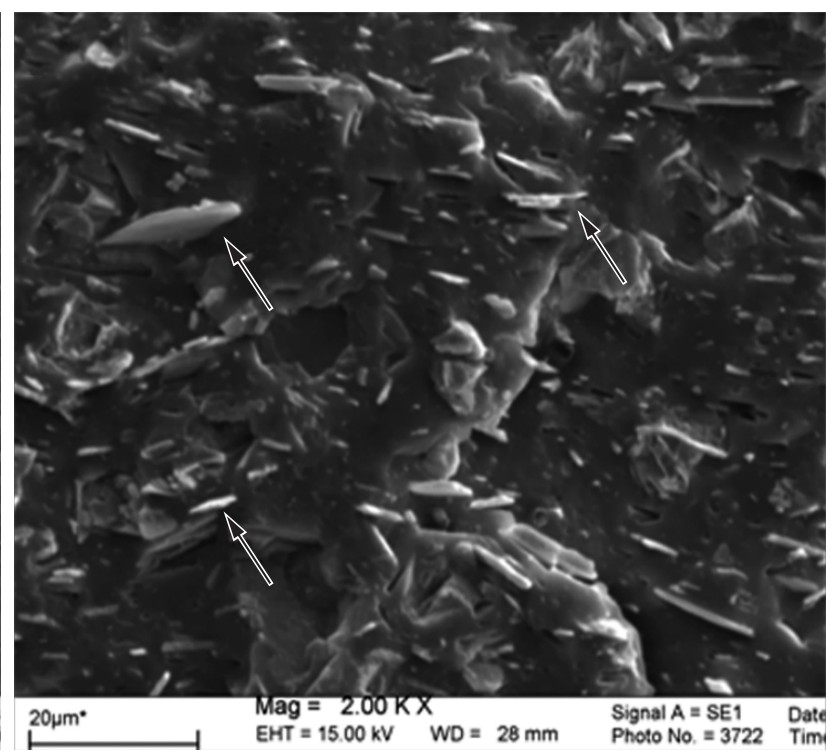

(d)

Figura 2. a) Membrana desenvolvida com base nas características anatômicas da região periodontal. A extremidade superior (seta) é mais espessa que a extremidade inferior (asterisco), formando uma curvatura interna. b e c) MEV da superfície da membrana de 50\% HAP + PHB após fabricação. b) Técnica de elétrons secundários evidenciando superfície pouco complexa com poros não interconectados (setas). c) Técnica de elétrons retroespalhados demonstrando que os grânulos de HAP não estão expostos na superfície (ausência de grânulos brancos). d) Superfície de fratura de compósito 35\% HAP + PHB. Cristais de HAP (setas indicam alguns deles) imersos na matriz do polímero PHB, onde não são observados poros.

peso: $25 \%$ de HAP em $75 \%$ PHB (membrana 1), $35 \%$ de HAP em $65 \%$ de PHB (membrana 2) e 50\% de cada biomaterial (membrana 3 ). Cada mistura foi separadamente inserida na máquina injetora para a fabricação das membranas pelo processo de moldagem por injeção, a pressão de 40 libras e temperatura entre 120 e $130^{\circ} \mathrm{C}$.

A cristalinidade das membranas foi analisada por difração de raios X. As análises foram realizadas em três amostras de cada membrana em difratômetro da marca Rigaku D-Max modelo Geiger Flex equipado com tubo de cobalto (radiação $\mathrm{Co}-\mathrm{K} \alpha$, $\lambda=1,79026 \AA$ ), com um monocromador de cristal curvo de grafite no feixe difratado, operado com diferença de potencial de $40 \mathrm{kV}$ e corrente elétrica de $30 \mathrm{~mA}$. As varreduras foram realizadas no modo passo a passo em intervalo de 15 a $50^{\circ} 2 \theta \mathrm{com} 0.05^{\circ}$ de incremento e 2 segundos de contagem de tempo em cada passo.
Para análise morfológica, foi utilizado inicialmente um microscópio eletrônico de varredura (MEV) da marca LEO 1430VP, a voltagens de 10 ou $15 \mathrm{kV}$. Para tal, as superfícies foram cobertas por uma camada de $20 \mathrm{~nm}$ de ouro, utilizando um sistema de deposição "sputtering balzers" (Electron Microscopy Sciences, modelo 550x). Foi também utilizado MEV ambiental (Hitachi SU6600) para análise da topografia de superfície e micro-análise elementar por espectroscopia por energia dispersiva de raios-X (EDS). As análises morfológicas foram realizadas em cada uma das membranas nas superfícies (a) da forma como foi fabricada, (b) da superfície de fratura e (c) da superfície após desgaste com broca odontológica diamantada (FG1016, KG Sorensen, Brazil). Esta última superfície foi incluída no estudo porque, no momento de implantação da membrana in vivo, o contorno interno das membranas será desgastado com broca para 
obter-se a justaposição adequada entre a membrana e a superfície óssea da mandíbula. Para a obtenção da superfície (b), uma máquina universal de teste Instron foi utilizada com a membrana posicionada de forma semelhante a um ensaio de flexão em três pontos.

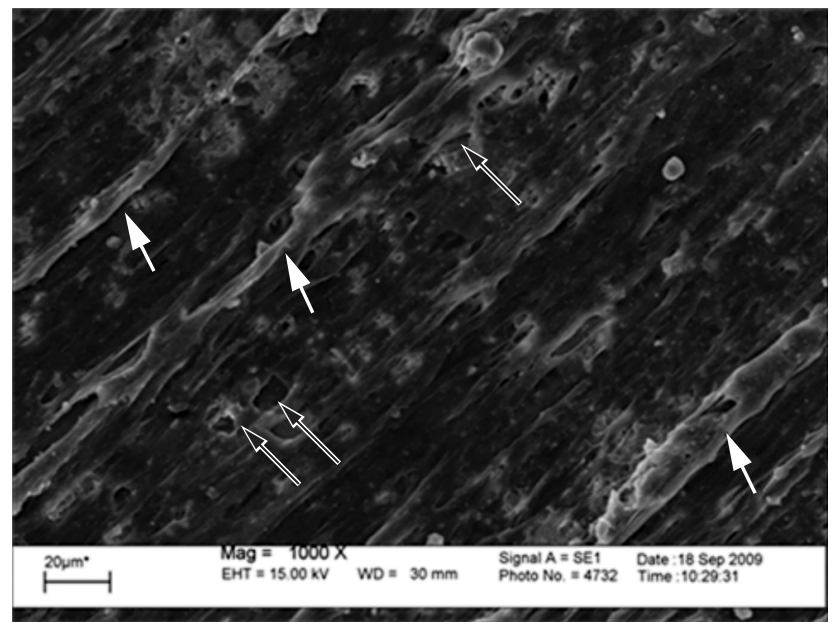

(a)

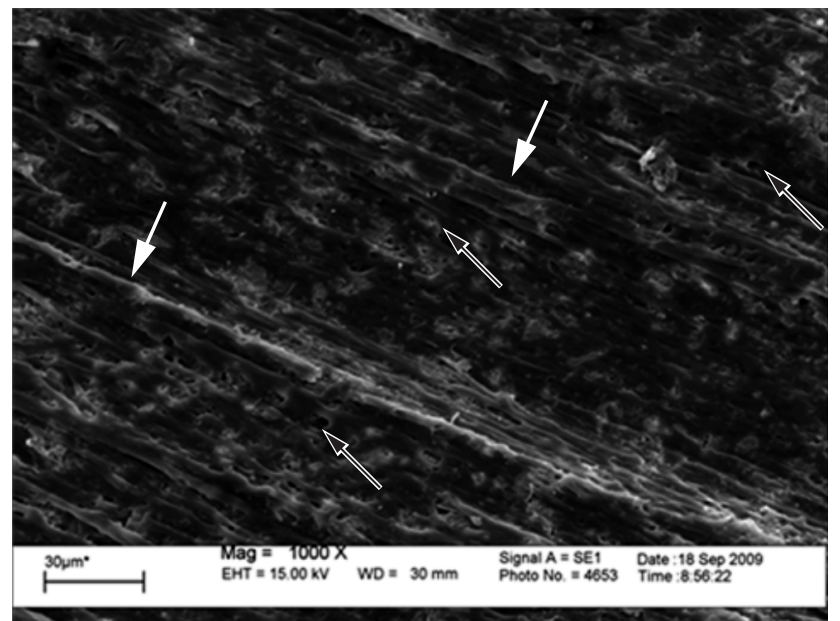

(c)

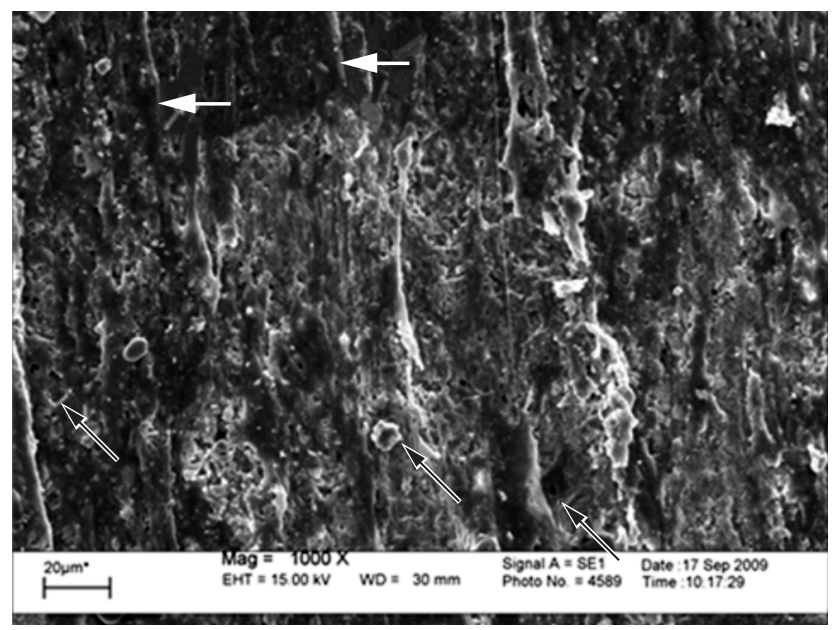

(e)
Para estimar o diâmetro dos poros, comprimento e espessura das estruturas nas superfícies das membranas foram obtidas 15 imagens em MEV por elétrons secundários de três amostras selecionadas de cada membrana 1, 2 e 3 . Essas imagens foram obtidas em

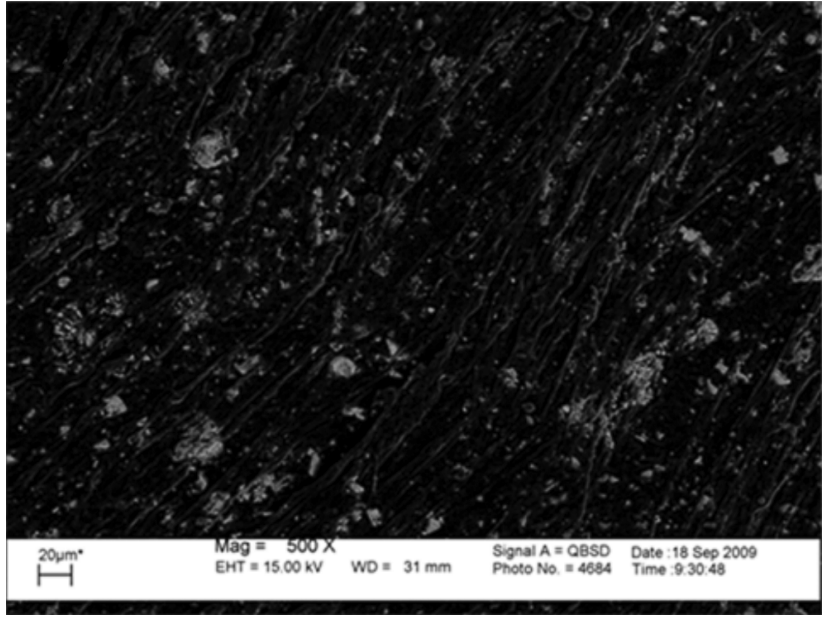

(b)

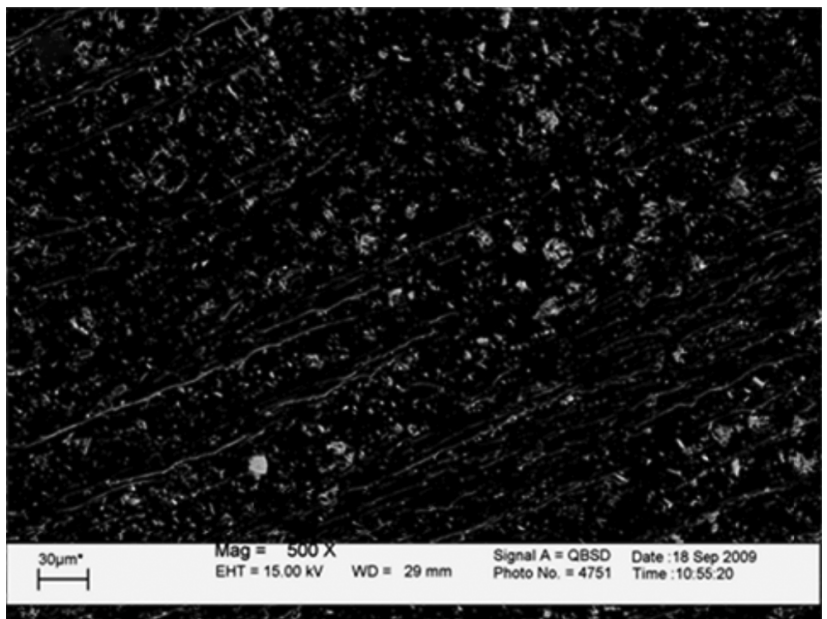

(d)

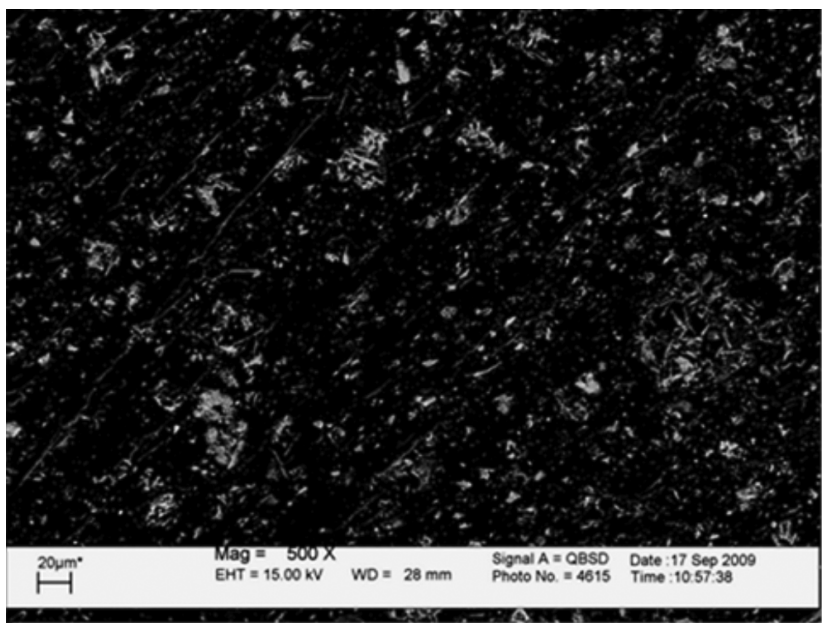

(f)

Figura 3. Superfícies dos compósitos de 25\% (a, b), 35\% (c, d) e 50\% (e, f) de HAP + PHB após conformação com broca odontológica. a, c, e) MEV por elétrons secundários onde se podem observar poros (setas finas) e estruturas lineares (setas brancas) formando complexa microtopografia de superfície. b, d, f) MEV por elétrons retroespalhados, evidenciando a HAP exposta (pontos claros) nas superfícies dos compósitos em meio à matriz de PHB (matriz negra). 
magnificação de 500×, sendo que em cada imagem, todas as estruturas (poros e linhas) foram medidas no software Analisys 5 (Olympus ${ }^{\circledR}$ BX51M). Com o mesmo software, mas em imagens obtidas no MEV por elétrons retroespalhados, as proporções de cristais de HAP e matriz de PHB presentes nas membranas 1, 2 e 3 foram estimadas utilizando-se a ferramenta de diferença de fases. Todos estes dados foram trabalhados na forma de média e desvio padrão, seguido da comparação entre as membranas 1, 2 e 3 por ANOVA um critério complementado pelo teste de Tukey, em nível de significância de $5 \%$.

\section{Resultados e Discussão}

Os difratogramas das membranas 1,2 e 3 são mostrados na Figura 1. Notam-se os picos altos e agudos, todos de acordo com a literatura para a HAP e o PHB e consistentes com o CPDS Card para a $\mathrm{HAP}^{[17-19]}$, demonstrando a alta cristalinidade dos

Tabela 1. Média e desvio padrão $(\mu \mathrm{m})$ do diâmetro dos poros e comprimento e largura dos elementos lineares na superfície das membranas após conformação com broca odontológica.

\begin{tabular}{cccc}
\hline & Poros $(\mu \mathbf{m})$ & \multicolumn{2}{c}{ Estruturas lineares $(\mu \mathbf{m})$} \\
\hline & & Comprimento & Largura \\
\hline $25 \%$ & $8,51 \pm 3,50$ & $73,35 \pm 30,04$ & $5,11 \pm 2,47$ \\
$35 \%$ & $6,61 \pm 2,69$ & $63,51 \pm 27,45$ & $3,55 \pm 1,14$ \\
$50 \%$ & $9,08 \pm 4,11$ & $75,98 \pm 30,76$ & $4,42 \pm 2,28$ \\
\hline
\end{tabular}

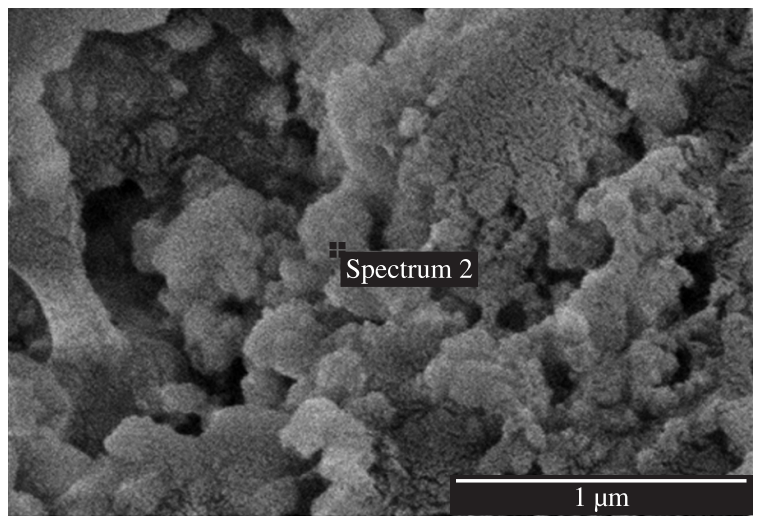

Electron image 1

(a)

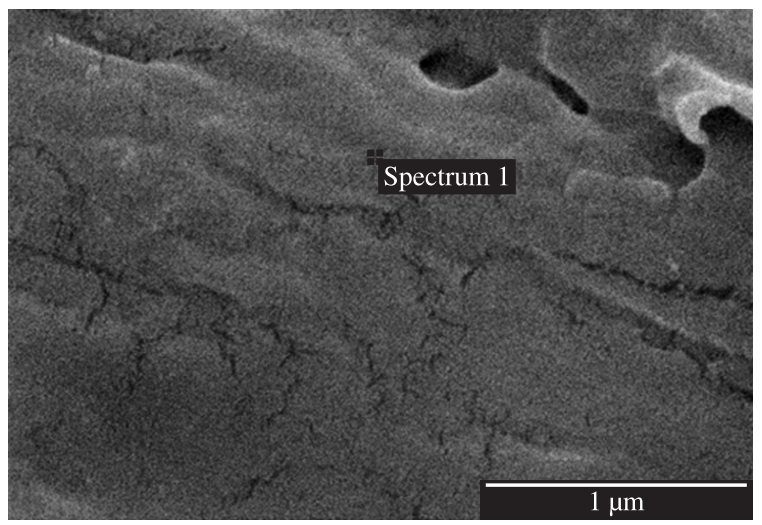

Electron image 1

(c) materiais. Sabe-se que o PHB é um polímero semicristalino e que, portanto, dá origem a cristais e fases amorfas, ambas identificadas nos difratogramas ${ }^{[19,20]}$. O conhecimento da cristalinidade de um biomaterial é de grande importância considerando que influencia o desempenho in vivo por afetar a reabsorção e suas propriedades mecânicas. Sabe-se que as regiões amorfas são reabsorvidas mais rapidamente que as regiões cristalinas e que materiais mais cristalinos têm geralmente taxa de reabsorção mais lenta. Materiais altamente cristalinos são geralmente mais frágeis por apresentarem menor módulo de elasticidade e, assim, com menor deformação antes da fratura ${ }^{[10,13,16,20,21]}$.

A morfologia macroscópica das membranas pode ser vista na Figura 2a. Para facilitar as manobras de desgaste com broca odontológica e a justaposição em uma região de anatomia muito variável (osso mandibular próximo ao dente em um defeito periodontal), a superfície interna das membranas foi desenvolvida na forma côncava, com a extremidade superior mais espessa do que a inferior. Na análise da superfície (a), observou-se pequeno número de poros não interconectados (Figura 2b). Pode-se notar, ainda, que os grânulos de HAP, apesar de presentes, não estavam expostos na superfície, pois estavam cobertos por fina camada do polímero (Figura 2c), assim como também observado por Mendonça et al. ${ }^{[9]}$. Esta superfície pode ser caracterizada como pouco complexa e, como tal, provavelmente não é a superfície ideal para promover a regeneração de tecidos por ser menos favorável à adesão do coágulo sanguíneo e adesão e atividades celulares ${ }^{[7,22]}$.

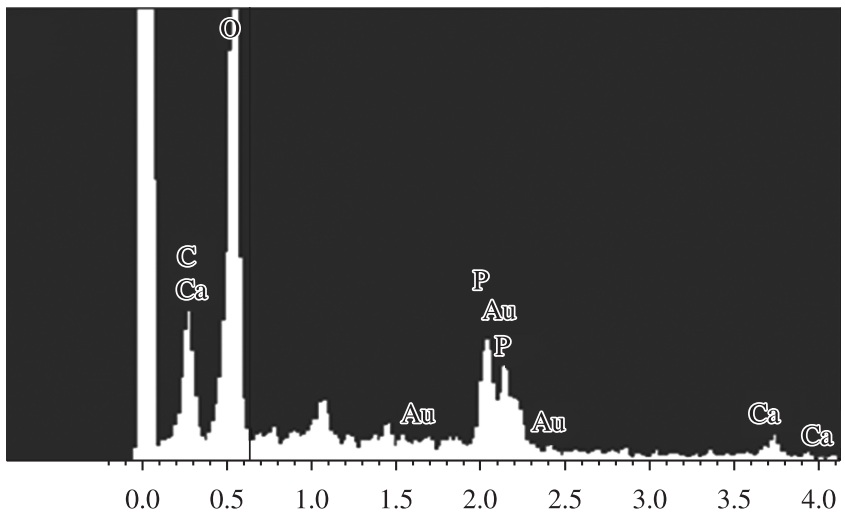

Full Scale 281 cts Cursor: 0.628 (13 cts)

(b)

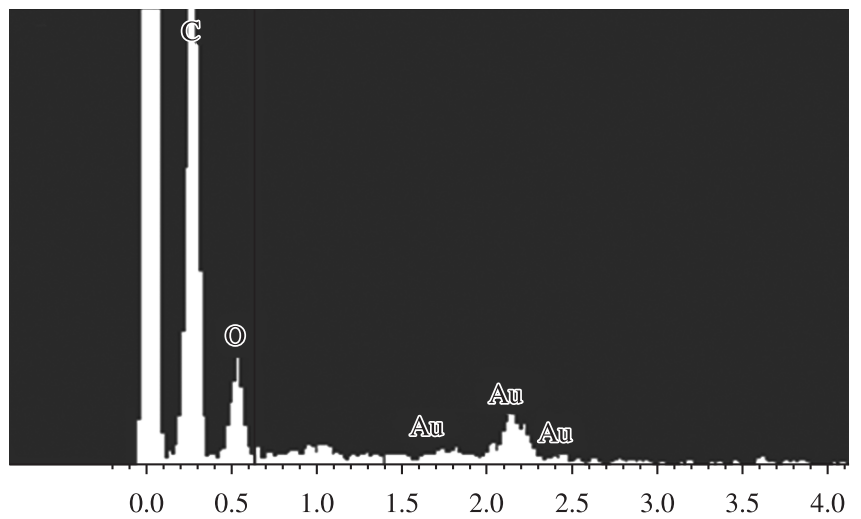

Full Scale 281 cts Cursor: 0.628 (8 cts)

(d)

Figura 4. Espectrometria de energia dispersiva de amostras de compósito de HAP + PHB. a) Feixe concentrado na superfície rugosa da amostra (Spectrum 2), com composição química demonstrando ser este um grânulo de HAP (gráfico em b). c) Feixe concentrado em superfície lisa do compósito (Spectrum 1), com composição química compatível com polímero de origem natural (gráfico em d). (Au representa o ouro utilizado para recobrir o material para MEV). 
As análises das superfícies de fratura das membranas permitiram observar os grânulos de HAP em meio à matriz homogênea de PHB, sem a presença de poros internos, ou seja, todas apresentavam estrutura compacta (Figura 2d). É importante notar que a estrutura interna do PHB pode apresentar poros com tamanhos que favorecem a osteocondução em torno de 150 e $500 \mu \mathrm{m}^{[23]}$, definida como a migração de células osteoprogenitoras ${ }^{[9,10,15,24]}$ ou poros muito pequenos para que ocorra a osteocondução ${ }^{[11]} \mathrm{e}$ ainda pode não ser poroso ${ }^{[16]}$ como aqui observado, características altamente influenciadas pelo método de fabricaçãa ${ }^{[9,11,15]}$. O método de fabricação utilizado neste trabalho, a moldagem por injeção, parte de uma mistura de dois biomateriais na forma de grânulos que se tornam viscosos pelas altas temperatura e pressão desta forma de processamento. Quando injetadas nessas condições nos moldes, o compósito ocupa todo o espaço disponível, portanto, a formação de poros internos é mínima ou inexistente ${ }^{[11]}$.

As superfícies das três membranas após a conformação com a broca odontológica (superfície C) apresentaram poros superficiais (que não se estendiam à estrutura interna da membrana) e estruturas lineares, que não estavam presentes nas outras superfícies. Estas estruturas distribuíram-se de forma uniforme pela superfície, sem agregados. Não existiram diferenças significantes no tamanho dos poros $(p=0,062)$ e na espessura $(0,059)$ e comprimento $(p=0,28)$ das estruturas lineares (Figura 3) (Tabela 1). Como estes elementos apresentaram tamanhos micrométricos, a topografia de superfície das membranas após o desgaste com broca odontológica pode ser caracterizada como microtopográfica ${ }^{[7,8]}$. A análise da superfície de compósitos de HAP e PHB com a finalidade demonstrada no presente trabalho ainda é inédita, contudo, diferentes materiais metálicos, poliméricos e cerâmicos tiveram suas superfícies caracterizadas como micro a nanotopográficas. Foi demonstrado que tais características favorecem a regeneração de tecidos periodontais por diferentes ações: i) maior adesão da matriz de fibrina do coágulo sanguíneo; ii) maior adesão e atividades plaquetárias, ambas resultando em maior migração de células progenitoras; iii) além de promover também uma maior adesão de osteoblastos $^{[7,8,10,22,25]}$. A matriz provisória formada pelo coágulo é o arcabouço para a formação de novos tecidos ${ }^{[1,4]}$. Dessa forma, espera-se que tal topografia de superfície atue mantendo o volume da matriz provisória por minimizar o processo de contração da matriz que normalmente ocorre durante a migração celular ${ }^{[7]}$. Assim, as células progenitoras poderiam ter maior volume de arcabouço para migrarem e formarem novos tecidos.

Por MEV com elétrons retroespalhados pode-se observar também que os grânulos de HAP estavam expostos na superfície C (Figuras 3b,d,f). As membranas fabricadas com maior proporção de HAP em peso apresentaram área de HAP exposta nas superfícies significativamente maior ( $\mathrm{p}<0,01): 10,6 \% \pm 2,4$ para membrana $3,6,9 \% \pm 0,9$ para membrana 2 e $3,2 \% \pm 0,6$ para membrana 1 . Diversos trabalhos abordam a bioatividade das cerâmicas, como a HAP, definida pela formação de ligação química entre o biomaterial e o tecido ósseo ${ }^{[10,11,21]}$. Contudo, outros trabalhos demonstram que a adição de cerâmica à superfície aumenta a resposta positiva da regeneração tecidual por conferir topografia de superfície mais complexa, independentemente da constituição química ${ }^{[7,8]}$. Por um destes mecanismos, ou talvez por ambos, a adição de cerâmica à matriz polimérica favorece a regeneração de tecidos, formando uma interface direta entre o tecido ósseo e o biomaterial, fator que determina a importância da maior proporção de grânulos de HAP expostos na superfície das membranas ${ }^{[10,15,22]}$.

A presença e proporção de HAP exposta nas superfícies das membranas influenciaram a topografia de forma que essas superfícies puderam ser caracterizadas como microtopográficas.
A Figura 4 mostra os espectros de EDS para diferentes regiões observadas no MEV, algumas mais rugosas e complexas e outras mais lisas. Observou-se que as regiões rugosas continham altas concentrações de cálcio, fósforo e oxigênio, compatíveis com a HAP de fórmula $\mathrm{Ca}_{10}(\mathrm{PO} 4)_{6}(\mathrm{OH})_{2}[10,22]$. Já nas regiões lisas, alto picos de carbono foram observados, demonstrando serem regiões

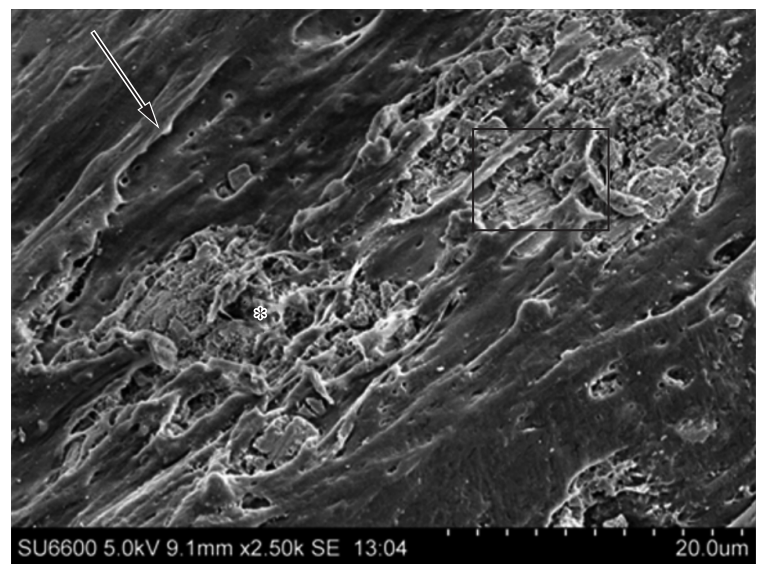

(a)

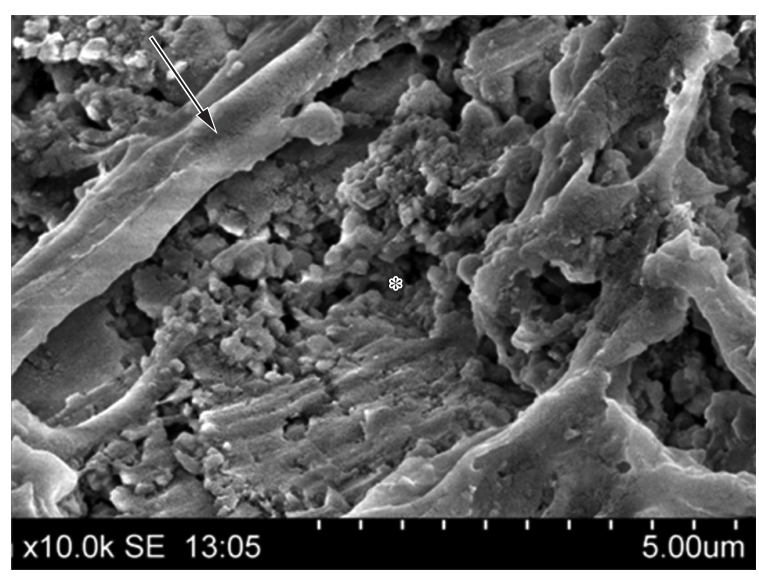

(b)

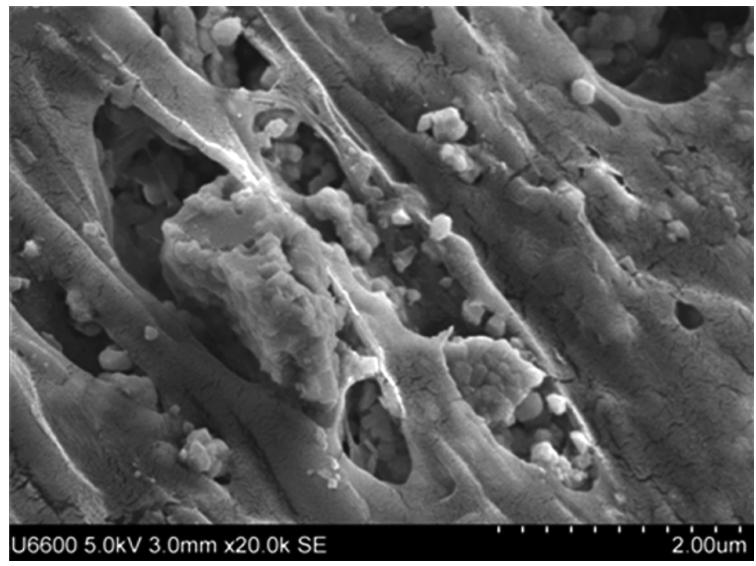

(c)

Figura 5. Fotos em MEV de superfícies dos compósitos de HAP + PHB. Compósito de 50\% de HAP + PHB após desgaste com a broca odontológica. Observa-se a interação de grânulos rugosos de $\mathrm{HAP}\left({ }^{*}\right)$ em meio à matriz lisa de PHB (seta) e a diferença na topografia de superfície dos dois biomateriais. b) Detalhe da área demarcada em (a). Pode-se observar projeções do PHB (seta) em meio à superfície rugosa da HAP (*). c) Em maior aumento, observa-se a interação entre a matriz lisa de PHB e os grânulos de HAP. 
constituídas pela matriz de $\mathrm{PHB}^{[10,22]}$. Essa diferença de topografia de superfície é evidente na Figura 5, onde as regiões contendo HAP são mais complexas que a matriz lisa de PHB. É importante notar que a matriz de PHB aderiu aos grânulos de HAP observada pelo contato direto e próximo destes biomateriais sem distâncias entre eles. Assim, a HAP e o PHB se mostraram compatíveis para a formação de compósitos como também relatado em outros trabalhos ${ }^{[10,22]}$.

\section{Conclusões}

A confecção de membranas rígidas de compósitos reabsorvíveis foi possível com a associação hidroxiapatita e polihidroxibutirato pelo método de moldagem por injeção. As membranas apresentaram alta cristalinidade e superfície com característica microtopográfica, onde a hidroxiapatita influenciou positivamente a complexidade topográfica das mesmas. O desgaste da superfície das membranas com broca odontológica expôs os grânulos de hidroxiapatita, contribuindo para maior complexidade topográfica.

\section{Agradecimentos}

Ao JHS Laboratório Químico pelo fornecimento de ambos os materiais e valoroso auxílio na concepção e fabricação das membranas. Ao Núcleo de Microscopia e Microanálise da Universidade Federal de Viçosa (UFV) pelo equipamento de MEV, ao Prof. Maurício Fontes da UFV pelo difratômetro e ao Prof. John Davies da University of Toronto pelo equipamento de MEV ambiental e EDS. À CAPES pela concessão da bolsa de doutorado e ao $\mathrm{CNPq}$ pelo financiamento do projeto.

\section{Referências Bibliográficas}

1. Wikesjö, U. M.; Sigurdsson, T. J.; Lee, M. B.; Tatakis, D.N. \& Selvig, K. A. - J. Calif. Dent. Assoc., 23, p.30 (1995). PMid:11392376.

2. Christgau, M.; Caffesse, R. G.; Schmalz, G. \& D'Souza, N. - J. Clin. Periodontol., 34, p.691 (2007). PMid:14724767.

3. Wikesjö, U.; Lim, W. H.; Thomson, R. C.; Cook, A. D.; Wozney, J. M. \& Hardwich, W. R. - J. Periodontol., 74, p.635 (2003). PMid:12816296. http://dx.doi.org/10.1902/jop.2003.74.5.635

4. Macedo, G. O.; Souza, S. L. S.; Novaes Junior, A. B.; Grisi, M. F. M.; Taba Junior, M. \& Palioto, D. B. - J. Periodontol., 77, p.46 (2006). PMid:17012487.

5. Owen, G. R. G.; Jackson, J.; Chehroudi, B.; Burt, H. \& Brunette, D. M. - Biomaterials, 26, p.7447 (2005). PMid:5785179. PMCid:2020314.

6. Liao, S.; Wang, W.; Uo, M.; Ohkawa, S.; Akasaka, T.; Tamura, K.; Cui, F. \& Watari, F. - Biomaterials, 26, p.7564 (2005). PMid:11568291.
7. Kikuchi, L.; Park, J. Y.; Victor, C. \& Davies, J. E. - Biomaterials, 26, p.5285 (2005). PMid:11337438. PMCid:31261.

8. Mendes, V. C.; Moineddin, R. \& Davies, J. E. - J. Biomed. Mater. Res., 90A, p.577 (2009). http://dx.doi.org/10.1002/jbm.a.32126

9. Mendonça, R. H.; Thiré, R. M. S. M.; Costa, M. F. \& Silva Filho, F. C. - Polímeros, 19, p.143 (2009).

10. Shishatskaya, E. I.; Khlusov, I. A. \& Volova, T. G. - J. Biomater. Sci. Pol. Ed., 17, p.481 (2006). PMid:13920503.

11. Boeree, N. R.; Dove, J.; Cooper, J. J.; Knowles, J. \& Hastings, G. W. Biomaterials, 14, p.793 (1993). PMid:3348186.

12. Pereira, A. P. V.; Vasconcelos, W. L. \& Oréfice, R. L. - Polímeros, 9, p.104 (1999). PMid:8632938.

13. Conz, M. B.; Granjeiro, J. M. \& Soares, G. A. - J. Appl. Oral Sci., 13, p.136 (2005). PMid: 18509122.

14. Rosa, S. D.; Franco, B. L. M. \& Calil, M. R. - Polímeros,11, p. 82 (2001). PMid:19332438.

15. Carlo, E. C.; Borges, A. P. B.; Del Carlo, R. J.; Martinez, M .M.; Oliveira, P. M.; Morato, G. O.; Eleotério, R. B. \& Reis Júnior, M. S. - J. Craniof. Surg., 20, p.853 (2009). http://dx.doi.org/10.1097/ SCS.0b013e3181a14c30

16. Duarte, M. A. T.; Júlio, C. F.; Martins, E. S. \& Pessin, S. H. - Rev. Mat., 9, p.386 (2004). PMid:10490438. PMCid:1718086.

17. Ni, J. \& Wang, M. - Mater. Sci. Eng., 20, p.101 (2002). PMid:16634688.

18. Mincryst. - "CPDS-2086". Disponível em: <http://database.iem. ac.ru/mincryst/s_carta.php?HYDROXY-LAPATITE>. Acesso em: 26 jun. 2010.

19. Oliveira, F. C.; Dias, M. L.; Castilho, L. R. \& Freire, D. M. G. - Biores. Technol., 98, p. 633 (2007). PMid: 16757104.

20. Vanin, M.; Santana, C. C.; Torriani, I. L.; Privelic, T. \& Duek, E. A. R. - Polímeros,14, p.187 (2004). PMid:17002488.

21. Wang, M.; Chen, L. J.; Ni, J.; Wneg, J. \& Yue, C.Y. - J. Mater. Sci.: Mater. Medic., 12, p.855 (2001). http://dx.doi.org/10.1023/A:1012899318688

22. Wang, Y. W.; Qiong, W.; Jinchun, C. \& Guo-Qiang, C. Biomaterials, 26, p.899 (2005). PMid:19547638. PMCid:2689583.

23. Ilan, D. I. \& Ladd, A. L. Op. Tech. Plastic Reconst. Surg., 9, p.151 (2003). http://dx.doi.org/10.1053/j.otpr.2003.09.003

24. Chen, G. Q. \& Wu, Q. - Biomaterials, 26, p.6565 (2005). http://dx.doi. org/10.1016/j.biomaterials.2005.04.036

25. Rosa, A. L.; Beloti, M. M.; Noort, R. V.; Hatton, P. V. \& Devlin, A. J. - Pesqui. Odontol. Bras., 16, p.209 (2002). http://dx.doi.org/10.1590/ S1517-74912002000300005

Enviado: 20/12/10

Reenviado: $28 / 04 / 11$ Aceito: 28/05/11 